\title{
Implementation of ICT at University Level during Covid-19 Pandemic: An Evidence from Yemen
}

\author{
Abdullah M. Al-Ansi \\ Faculty of Education, Thamar University, Yemen \\ ebrar.ansi@yahoo.com
}

\begin{abstract}
Integration of ICT in higher education has a significant role after the full transition to remote learning during the outbreak Covid-19 pandemic. This research aims to investigate the impact of the internet accessibility, management system, e-learning infrastructure, and organization ICT policy on the integration of ICT usage during the Covid-19 pandemic among the faculty members and students of Thamar University, Yemen. A quantitative approach was used to collect data by conducting online surveys. Participants of the surveys were 264 educators, staff, and students of Thamar University. Data were analyzed using different statistical techniques including descriptive statistics, exploratory factor analysis, correlation, and multiple regressions to determine the impact of interaction among variables. Results reveal evidence that internet accessibility, management system, and infrastructure have a significant positive impact on the integration of ICT in higher education. In addition, integration of ICT with the university's Policies has an insignificant negative impact on the usage of technology. Furthermore, these results give significant evidence of transition to virtual learning in developing countries generally. Practical implications contributed by this research include the practice of using ICT as an instruction tool during the pandemic by adopting ICT infrastructure, access to the internet, developing learning management systems, and implementing the right policies. Finally, both ministry of education, higher education institutions are recommended to take responsibility in facilitating and supporting e-learning systems continuously as long as this pandemic has yet lasted.
\end{abstract}

Keywords: ICT, Internet accessibility, Management system, Infrastructure, ICT policies, Higher education

\section{Introduction}

Using ICT in education became a significant role to conduct virtual learning during the outbreak of the covid-19 pandemic. Factors of ICT play an important role in effective distance learning. Technology does not only support creating new knowledge but facilitates problem-solving and enhances the human capacity to work effectively as well [1]. At the higher education level, significant growth in the use of Information and Communication Technology (ICT) has been seen in recent years especially during Covid-19 [1][2]. It has reshaped the teaching-learning process [3]. According to De-Corte et al. (2003), the use of ICT makes the classroom learning environment more interactive, engaging, and conducive for independent learning. Teachers are using ICT to facilitate learners by using modern teaching

Article history:

Received (April 16, 2021), Review Result (May 15, 2021), Accepted (June 21, 2021) 
tools and resources. They are also using ICT to develop interpersonal skills among learners [4].

However, the integration of ICT into classroom instruction is not as simple as it seems. The integration process is complicated and challenging for teachers and administrations as implementers. Several studies have established what these hurdles are in various ways and cultures [5]. Such as discrepancy between existing ICT resources and existing curricula, poor administrative support, Unavailability of financial resources, lack of opportunities for training in the field of ICT, technophobia, personal beliefs, knowledge, and attitude of teachers about the use of technology, attitude towards acceptance of change, irresistible workload, lack of instructional support in the curriculum about the use of ICT, outdated ICT infrastructure [6].

Factors related to the use of ICT are placed into two categories: external factors such as lack of available time and the scarcity of technical resources and financial resources, professional development opportunities; administrative support along with internal issues such as teachers' beliefs, values, and attitude; fear of change and negative perception about ICT; teachers` self-efficacy and professional commitment [7]. Another approach to group the factors is to consider whether it concerns the employee (e.g., instructor`s level) or the agency (e.g., school-level barriers), such as a shortage of access to quality information and inefficiency in instruction and technological issues [8]. Change in one factor affects change in other factors as well.

Previous studies have important evidence about the impact of the internet accessibility, management system, e-learning infrastructure, and organization ICT policy on the integration of ICT usage. What makes this research different is that this research has been conducted during the Covid-19 pandemic where the education process has been transformed completely into virtual learning. Using the internet and learning management systems are not options anymore. Distance learning is depending on the infrastructure of ICT and the internet. The infrastructure of ICT includes theories and practices, electronic tools and devices, LMS, connectivity, and resource availability [2]. Furthermore, ICT policies made by both government and educational institutions also have an impact on the learning process in higher education. Developed countries have invested more in higher education than developing countries where there is a lack of infrastructure, financial support, and experiences [9]. So, this research includes this objective to understand the change in these important factors of ICT and its integration in the higher education learning process.

\section{Literature review}

\subsection{ICT in developing countries}

Unlike many other countries, some Middle East countries especially Yemen have not made significant investments intending to enhance public education. Teaching was not expanded well by revising the curriculum or adding new electronic devices to the public education system [10]. This initiative has incorporated training and developmental services for educators to apply information and communication technologies [11]. According to Alshmrany and Wilkinson, the use of ICT is new in Yemen. Unlike other developed countries, Yemen lacks effective ICT programs, especially at the primary level [12].

However, the Government of Yemen is striving hard to improve the educational practices to meet global demands, especially by integrating ICT in education at a high level by giving it utmost priority. On the other hand, ICT at the secondary level of education has been recently implemented when a government project was introduced for Public Education. Therefore, 
ICT integration at the primary level needs attention. Bari remarks that the aforementioned negligence at the primary education level in Yemen continues when we compare it with the secondary and tertiary level, which have brought about a drastic change after mandated leadership programs for ICT integration. Strategic planning is required to introduce ICT at the primary level [13]. To achieve this goal, teachers must have a positive attitude towards ICT adoption irrespective of the education level, which is the key to success. Commitment by teachers and administrative support together will help bring about a change in the education system of Yemen.

Similarly, Alharbi and Lally pronounce that the education ministries in developing countries have acknowledged the significance of ICT integration at all levels of education [11]. Therefore, an effort has been made to reform and restructure the education system at the university level as ICT integration in Education is slow despite continuous efforts and investments by the Government of Yemen [14]. Muzafar and Jhanjhi mention that several egovernments projects in Yemen have been introduced for ICT integration in education, e.g., 'Yesser', 'Saudi Portal', and 'Amer'. They also highlight that mainly Digital Transformation Program is one an important goal to achieve objectives as the government vision is to establish a digital government so the country becomes a global ICT hub [15]. Equally important, educational policies developed so far need to be reformed to integrate ICT in education at all levels.

Despite all this vast expenditure and governmental support, Yemen is still lagging behind the educational sector leaders, particularly in Information and communications technology [16]. ICT also has a significant penetration in Yemeni higher education which remains to be addressed. However, research proved that heavy investment in the integration of technology does not ensure implementation in organizations. For this purpose, administrative support and teachers ' belief and commitment play an important role and ensure the maximum level of implementation and integration [17].

\subsection{Theoretical review}

Theoretically, infrastructure and resources play a vital role in integrating ICT in teaching pedagogy [16]. In their study, they found that lack of funding to purchase hardware and software is also one of the reasons that teachers do not use technology in their classrooms. The availability of computers and their usability have a direct connection with each other. They also found that teachers who have access to computers in their institutes integrate technology in their lesson plan effectively.

Fishbein and Ajzen first suggested the "Principle of Reasoned Action" and proposed the theory of "Reasoned Action (TRA)" to explain human modes of behavior [18]. It was intended to describe general human behavior across broad domains [19]. In their actual use of technology, TRA was widely used and also modified to assess individual choices and expected behavioral patterns [20]. However, the theory of reasoned action (TRA) is constituted by three main constructs: these are behavioral intent, actions, and subjective norm.

Inadequate technical supports also create stress among teachers, which might affect teachers' readiness to integrate technology [21]. About the importance of the technical coordinator, Smerdon et al. stated that the absence of technical support hindered teachers to integrate technology in the classroom. It was also confirmed from their study that teachers who were provided technical support proven to be better than teachers who were not provided technical support [22]. A similar result was found by Tar that those teachers who have the facility of computers and internet in their institute are still not using them in their lecture daily 
as they were not provided technical support to handle those hardware and software [23]. Teachers must have clear ICT policies before they design their pedagogy to integrate technology, so they can reflect and evaluate their practices in the light of those policies [13].

Furthermore, Commitment has been described by scholars as "attachment or alignment psychologically towards the change rather than showing acceptance for any kind of change" [24]. As per Herscovitch and Meyer, Piderit, and Straub, commitment to change is complex, which consists of sentimental as well as social aspects. According to Kopcha, scholars and educators play a vital role in preserving complexities pertaining integral process of integrating technology [25] [26]. Amoako-Gyampah et al. affirm that technology is implemented successfully on certain dependent factors, especially support and encouragement given to staff by top management and administration [27].

Inadequate technical supports also create stress among teachers, which might affect teachers' readiness to integrate technology [21]. About the importance of the technical coordinator, Smerdon et al. stated that approximately $68 \%$ of the teachers who were surveyed claimed that the absence of technical support hindered them to integrate technology in the classroom [22]. Findings also suggest that teachers who were provided technical support proven to be better than teachers who were not provided technical support. Availability of technology resources is not enough until the technical support of using hardware and software is not provided to teachers. One of the studies conducted by Japhet and Usman found that those teachers who have the facility of computers and internet in their institute are still not using them in their lecture daily as they were not provided technical support to handle those hardware and software [4].

Teachers cannot make improvements on their own, particularly if they are not provided administration's support. The administration must provide training to the teachers so that they can use computers and plan their lessons accordingly [28]. Leaders are responsible to motivate their staff towards integration technology in their teaching by providing them professional development workshops [14]. According to Munir and Khan, the non-supportive administrative staff is one of the main hindrances which prevent teachers to integrate ICT in their teaching [29]. The active technology program needs help from the entire organization [30]. This was also discussed in the study conducted by Harasim that those institutes where administration includes technical support in their long-term plan, promote technology in their teaching, especially in online teaching in a better way as compared to those where administration support is absent [31].

The importance of this research is to investigate the differences in using ICT during the Covid-19 pandemic where all educational institutions have been forced to adopt distance learning as a solution to overcome the consequences of the pandemic. Based on the previous studies and empirical findings, this study intends to answer the following research question: How well 'commitment in the use of technology can be predicted from a combination of four variables: 'Internet accessibility', 'Management System', 'Infrastructure, and 'organization ICT policy' among the faculty members of one selected public university in the Republic of Yemen? 


\subsection{Research hypotheses}

The following hypotheses are formulated based on the discussed literature and empirical findings.

H1: Internet accessibility plays a positive role in the integration of ICT in higher education.

$\mathrm{H} 2$ : Management system has a positive impact on the integration of ICT in higher education

H3: Infrastructure has a positive impact on the integration of ICT in higher education.

H4: ICT Policies play a positive role in the integration of ICT in higher education.

The following model to determine the external organization factors that influence the commitment in the use of technology is given below:

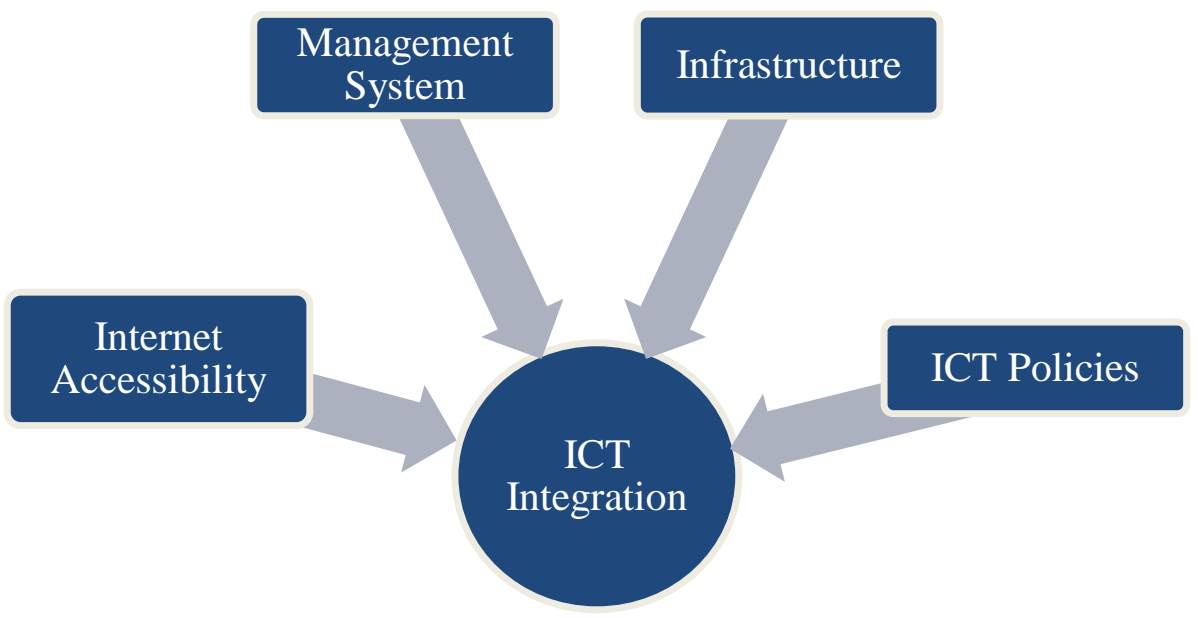

Figure 1. Conceptual framework of research hypotheses

\section{Materials and method}

The current study was explanatory in the characteristic wherein the effect of predictors on the outcome variable was predicted [32]. In other words, "studies that establish a causal relationship between variables may be termed explanatory research" [33]. The measurement model comprises five dimensions, for instance, internet accessibility, 'Management System', 'Infrastructure', 'organization ICT policy', and 'commitment in the use of technology. These five dimensions are used to measure external factors in the academic context of one selected public university. Furthermore, based on the preceding literature, figure one exhibits the relationship between organization external factors and the 'commitment in the use of technology. The basic regression model is written as follows:

$$
y n=\alpha+\beta x n+\varepsilon
$$

In the above equation, $\mathrm{y}$ represents an outcome variable and $\alpha$ denotes the intercept term. $\mathrm{X}$ represents predictors, $\beta$ denotes the regression coefficient while $\varepsilon$ is the error term. The basic operational form of the current study model is represented as follows: 
'Commitment in use of technology' = (Internet Accessibility, 'Management System', 'Infrastructure' and 'organization ICT policy').

Based on the above explication, the following regression model is executed in this study:

$$
C U T=\alpha \circ+\beta 1(I A)+\beta 2(M S)+\beta 3(I N F R A)+\beta 4(O P)+\varepsilon
$$

\subsection{Instruments}

The objectives of the current study were to ascertain the association and current trends between research variables, therefore, adopted a quantitative approach. To do so, a quantitative method by survey technique is chosen to answer the research question. A quantitative study aims to observe a population or phenomenon that is completed at one point in time [34]. In addition, the survey technique is used to provide scientifically collected data as a basis for researchers since it counts on empirical evidence [35]. In this design, the data are collected concurrently and answered at the same time in contrast to experimental design wherein data is collected in different phases [36].

A self-completion instrument written in Arabic and English was used. There was a total of 32 items in a questionnaire. The number of items fulfills the minimum requirement in a research instrument [37]. To strengthen the face and content validity of the instrument, it was given to five assistant professors of the College of Business Administration and College of Arts. These experts assure the content validity, face validity, and translation of each item. The questionnaire was translated two times by using a Delphi technique wherein they provide their discernment and accurate summary based on their structured communication [38]; [39]; [40]. Hence, it was translated and back-translated to ensure translation of scale's accuracy. After getting approval from experts, the instrument was finally ready to disseminate to the respondents.

\subsection{Reliability test}

In our study, the reliability of the instrument is enhanced by using four steps: clear hypothesized constructs, accurate level of measurement, multiple indicators, and pilot-testing [41]. As evident in [Table 1] the initial reliability of the research instrument was found out by computing Cronbach Alpha using SPSS version 22 over 30 records in a pilot study which were not included in the main study. The value was found significant i.e., 0.916 which is considered satisfactory as proposed by [42]; [43]; [44]. Moreover, the inter-item correlation of each variable was also computed.

Table 1 . A readability analysis of a pilot study

\begin{tabular}{|c|c|c|c|c|}
\hline No. & Variables & Indicators & Cronbach Alpha & Overall \\
\hline 1. & Internet Access & 9 & 0.874 & \multirow{6}{*}{$\begin{array}{l}\text { Cronbach Alpha for all } \\
\text { Indicators }\end{array}$} \\
\hline 2. & Management System & 9 & 0.834 & \\
\hline 3. & Infrastructure & 10 & 0.876 & \\
\hline 4. & University Policies & 8 & 0.923 & \\
\hline \multirow[t]{2}{*}{5.} & Integration of ICT & 12 & 0.765 & \\
\hline & \multicolumn{3}{|c|}{ Total $\mathrm{N}=30$ participants } & \\
\hline
\end{tabular}

The selected sample has to be represented of the target population since it yields more valid and reliable results [45]. Besides, it is upon researchers' discretion to decide the sample size based on the target population [32]. All university employees (faculty members) of a selected public university were taken as a target population. Non-teaching and clerical staff 
were not part of the study. The unit of analysis was the faculty members employed in the selected universities of the Republic of Yemen.

\subsection{Data collection procedure}

A sample of 264 full-time employees having administrative and teaching responsibilities participated using a self-completion questionnaire. After getting ethical approval [46] from the research ethics standing committee, the survey link was forwarded to the university IT department and from there it was shared to the employees of the university using an exponential non-discriminative snowball sampling technique where one participant recruits another participant [47]; [36]. To expedite the data collection, the same link was forwarded to employees' social groups and requested to forward to their respective social groups and so on. Due to the current pandemic situation, the university allows only administrative, teaching, and non-teaching staff members to visit their department and perform their official duties. Teaching is carried out using a learning management system titled blackboard ever since the outbreak of Covid-19. However, online data collection methods were kept into consideration. Data was collected using a Google drive form started in the last week of December 2020 and was completed in the first week of March 2021. Approximately, ten weeks were expended in data collection. At the time of data collection was stopped, two hundred and ninety-three i.e., $84 \%$ were gathered on Google form, and fifty-five i.e., $16 \%$ were collected face-to-face.

\subsection{Measurements}

Commitment to the use of technology was measured through four items adapted from Bulut and Culha [17]. Sample items include: "My manager can be counted on to help me develop the skills emphasized in training programs," "I can expect my manager to assign me to special projects requiring the use of the skills and knowledge," and "My manager enthusiastically supports my participation in training programs". The internal consistency coefficient (Cronbach $\alpha$ ) for this scale was 0.765 (4 items). There was a total of six items before factors loading. A five-point Likert scale ranging from 1 (strongly disagree) to 5 (strongly agree) was used to measure this outcome variable.

Internet accessibility was measured through three items adapted from Seifu, [48]. Sample items include: "There is an E-learning system with the necessary internet speed," "E-learning through internet access helps teachers enhance the knowledge of ICT equipment," and "Internet access helps teachers and students develop the skill to operate ICT facilities and software". The internal consistency coefficient (Cronbach $\alpha$ ) for this scale was 0.874 (3 items). There was a total of six items before factors loading. We used a five-point Likert scale ranging from 1 (strongly disagree) to 5 (strongly agree) to measure this predictor variable.

Management System was measured through four items adapted from [48]. Sample items include: "Management System design and plan to integrate ICT into the teaching-learning process," "Administration implement ICT plan in collaboration with teachers," and "Management system provides professional development opportunities." The internal consistency coefficient (Cronbach $\alpha$ ) for this scale was 0.834 (4 items). There was a total of seven items before factors loading. A five-point Likert scale ranging from 1 (strongly disagree) to 5 (strongly agree) was used to measure this predictor variable.

Infrastructure was measured through three items adapted from Akubulut et al., [28]. Sample items include: "Internet speed is sufficient in our campus," "Computers are fast enough to use for instructional activities," and "There are sufficient licensed software programs." The internal consistency coefficient (Cronbach $\alpha$ ) for this scale was 0.876 (3 
items). There was a total of seven items before factors loading. We used a five-point Likert scale ranging from 1 (strongly disagree) to 5 (strongly agree) to measure this predictor variable.

ICT Policies were measured through two items adapted from Akubulut et al., [28]. Sample items include: "There is a wide-ranging policy in supporting ICT integration in teaching," "There are policies that used ICT for teaching and learning in specific subjects," and "There would be discussions with teaching staff about ICT use for instructional purposes." The internal consistency coefficient (Cronbach $\alpha$ ) for this scale was 0.923 ( 2 items) after factors loading. There was a total of six items before factors loading. We used a five-point Likert scale ranging from 1 (strongly disagree) to 5 (strongly agree) to measure this predictor variable.

\section{Results}

\subsection{Statistical procedures}

Statistical Package for Social Sciences (SPSS) 22nd version was used for descriptive and inferential statistics. First, descriptive statistics were executed to know respondents' demographics. Their mean, standard deviations, frequency, and percentage were observed. Exploratory Factor Analysis (EFA) was first performed to reduce 32 Likert-type items into the requisite five factors. Then, Pearson correlation ( $r$ ) and reliability statistics of loaded items were analyzed. Lastly, regression analysis was used to test hypothesis and model fitness (Perry, 2017).

\subsection{Data screening and removal of outliers}

In the initial screening, no missing or out-of-range values were found in the data set due to restricted options used in Google form. Respondents may not proceed to the next item or page if they missed any item to be filled inadvertently. 48 univariate and multivariate outliers were identified and removed from the main data set before inferential analysis by using standard Zscore [3.29 in absolute value] and Mahalanobis distance $\chi 2$ value at $\mathrm{p}<0.001$. According to Tabachnick and Fidell, "Cases with a standardized score over $3.29(\mathrm{p}<.001$, two-tailed test) are potential outliers" (p.73). They further elucidate that "A very conservative probability estimate for a case being an outlier, say, $\mathrm{p}<.001$ for the Chi-square value is appropriate with Mahalanobis distance" (p.74).

\subsection{Descriptive statistics}

Descriptive statistics results are shown in [Table 2]. A total of 264 usable responses were included in the analysis which includes 123 (46 percent) who were female and 141 (54 percent) were male respondents $(\mathrm{M}=1.350, \mathrm{SD}=0.477)$. Other demographics included group types which were under 3 categories: lecturers, staff and students, qualifications, and faculty where they are teaching/ studying or working. 
Table 2. Demographics of sample

\begin{tabular}{|c|c|c|c|}
\hline No. & Demographics & Frequency (f) & Percentage (\%) \\
\hline \multirow{2}{*}{1.} & Gender: Female: & 123 & $46 \%$ \\
& Male: & 141 & $54 \%$ \\
\hline \multirow{3}{*}{2.} & Group type: Educators & 42 & $16 \%$ \\
& Staff & 34 & $13 \%$ \\
& Students & 188 & $71 \%$ \\
\hline 3. & Qualifications: Ph.D. & 22 & $9 \%$ \\
& Master & 30 & $11 \%$ \\
& Bachelor & 212 & $80 \%$ \\
\hline & Faculty: Education & 78 & $30 \%$ \\
& Management & 65 & $24 \%$ \\
& Engineering & 46 & $18 \%$ \\
& Computer & 40 & $15 \%$ \\
& Applied Science & 35 & $13 \%$ \\
\hline
\end{tabular}

\subsection{Multicollinearity - correlation}

Pearson correlations between independent variables are shown in [Table 3]. This correlation was performed to check the multicollinearity issue in our model. Due to the weak correlation between independent variables, no multicollinearity exists in our hypothesized model. Multicollinearity exists if correlation among independent variables is equal to or greater than 0.90 [49][50].

Cronbach alpha of each factor (loaded items) was computed after factor analysis. Cronbach coefficient Alpha of factor 'commitment in the use of technology' was 0.894, 'Management System' was 0.882 , 'Infrastructure' was 0.846 , 'Internet Accessibility' was 0.790, and 'organization ICT policy' was 0.860 . The overall reliability of predictors (12 indicators) was 0.852 and the sum of all indicators i.e., 16 items after loading was 0.889 . Before hypotheses testing, a correlation coefficient was computed to assess the association between variables.

Table 3. Correlation between independent variables

\begin{tabular}{|c|c|c|c|c|c|c|c|}
\hline Independent Variable & $\mathrm{M}$ & $\mathrm{SD}$ & $\mathrm{IA}$ & $\mathrm{MS}$ & Infra & UP & ICT \\
\hline Internet Access & 4.10 & 0.843 & 1 & & & & \\
\hline Management System & 3.89 & 0.963 & $.534 * *$ & 1 & & & \\
\hline Infrastructure & 3.45 & 1.213 & $.467 * *$ & $.378^{* *}$ & 1 & & \\
\hline University Policies & 3.87 & 0.953 & $.403 * *$ & $.310^{* *}$ & $.453 * *$ & 1 & \\
\hline Integration of ICT & 4.47 & 0.826 & $.543 * *$ & $.498^{* *}$ & $* 522^{* *}$ & $.218^{* *}$ & 1 \\
\hline
\end{tabular}

[Table 3] shows means, standard deviations, inter-correlations for commitment in the use of technology and its predictors i.e., 'external organization factors'. It is evident from Table III that there is a positive high (Cohen, 1988, pp.79-81) a correlation existed between Internet Accessibility and commitment in use of technology $(\mathrm{r}=0.543 ; \mathrm{n}=264 ; \mathrm{p}=0.000)$, Management System and commitment in the use of technology $(r=0.498 ; n=264 ; p=$ 0.000), a positive moderate (Cohen, 1988, pp.79-81) correlation existed between the Infrastructure and commitment in the use of technology $(r=0.522 ; n=264 ; \mathrm{p}=0.000)$, a 
positive weak (Cohen, 1988, pp.79-81) correlation found between ICT Policies and commitment in use of technology $(r=0.218 ; n=264 ; p=0.001)$.

\subsection{Common method bias}

In the existing literature, the threats of the consequence of method biases have long been argued (e.g., Johan and Crane, 1975; Campbell and Fiske, 1959; Fiske, 1982; Greenleaf, 1992; McGuire, 1969). A common method bias is not only a substantial issue but also a key cause of measurement error and has a momentous influence on research findings [51]. A common method bias is problematic since it may inflate or deflate the correlation among predictors and outcome variables due to the common method employed for data collection Campbell and Fiske, (1959). Therefore, we test for common method biases using Harmon's single-factor test on predictors and outcome variables. To do so, we executed the test in SPSS opting for principal axis factoring without rotation, setting the numbers of factors to be one. We found out that the total number of variances explained is $34.442 \%$. This suggests that our study has no issue of common method biases since the variance explained is less than $50 \%$ according to Harmon's single-factor test assumption.

\subsection{Kaiser-Meyer-Olkin and Bartlett's tests}

The acceptability of data was calculated before conducting an exploratory factor analysis. Therefore, sampling adequacy was checked using Kaiser-Meyer-Olkin (KMO) and Bartlett's tests before exploratory factor analysis. The value of KMO for all indicators of our study is 0.849, which indicates the satisfactory threshold limit i.e., 0.70 (Foster et al., 2006; Leech et al., 2005). Besides, Bartlett's test was also performed to check whether a correlation matrix is significantly dissimilar from an identity matrix (Bartlett, 1951; Bartlett, 1954; Leech et al., 2005; Tabachnick and Fidell, 2007). Our analysis revealed that, Bartlett's test of sphericity wherein (approximate Chi-square $=3002.548$, degree of freedom $=120, \mathrm{p}<0.000$ ) confirms that the correlation matrix is significantly different from an identity matrix.

\subsection{Exploratory factor analysis (EFA)}

To validate the constructs and to ensure convergent, construct, and discriminant validity, an exploratory factor analysis data reduction technique was executed. This technique was used to draw five variables. In factor analysis, a large set of variables reduce and summarize the data into a smaller set of components [50]. To carry out this objective, we have used the 'Principal components' factoring option. The initial solution was rotated using varimax orthogonal rotation with the Kaiser Normalization method. This step is executed to lessen questionnaire Likert-based items into the requisite five factors. Tabachnick and Fidell (2007) point out that "The goal of the varimax rotation is to maximize the variance of factor loadings by making high loadings higher and low ones lower for each factor" (p.620).

A total of 32 Likert-scale items related to external factors in our measurement model is categorized into five groups. Consequently, only 16 items were loaded onto their variables: Commitment in use of technology (four items), Management System (four items), Infrastructure (three items), Internet Accessibility (three items), and ICT Policies (two items). In our study, all loaded items were greater than $|.50|$ which indicates a very robust convergent and construct validity (Cooper et al.; Field [45]; and is considered significant for further analysis (Kaiser) as shown in [Table 7]. The least factor loading was 0.699 (i.e., MS6) which is exceeding the suggested limit of 0.50 . Besides, the average factor loadings are more than 
0.70 for each factor as recommended by Tharenou et al. [52]. In [Table 4], factor loadings less than $|0.40|$ were deleted to sustain clarity. It is worth noting that the statistical significance of factor loadings is not computed by SPSS Field it is, however, the sample size which points out the factor's loadings statistical significance [53]. Consequently, it can be concluded that the convergent and construct validity of the factors of our study has been confirmed.

Since there are no cross-loadings in the 'Component Transformation Matrix' hence the discriminant validity is also proven [52]. The eigenvalue of five variables is greater than 1.0 endorses that they are useful and function as an independent factor. The first factor, 'commitment in the use of technology is strong, with a high eigenvalue of 3.226 , and it accounted for 20.162 percent of the variance. The second factor that is, 'Management System' has an eigenvalue of 2.961 and it accounted for 18.509 percent of the variance. The third factor to be exact is, an 'Infrastructure' has an eigenvalue of 2.384 and it accounted for 14.900 percent of the variance. The fourth factor namely 'Internet Accessibility' has an eigenvalue of 2.109 and it accounted for 13.183 percent of the variance. Lastly, the fifth factor 'organization ICT policy' has an eigenvalue of 1.861 and it accounted for 11.631 percent of the variance. To conclude, all factors cumulatively accounted for above 78.385 percent of the total variance.

Table 4. Rotated component matrix

\begin{tabular}{|c|c|c|c|c|c|}
\hline Items & ICT & MS & Infra & Inter-Access & Univ-Policy \\
\hline ICT5 & 0.862 & & & & \\
\hline ICT2 & 0.860 & & & & \\
\hline ICT1 & 0.844 & & & & \\
\hline ICT6 & 0.708 & & & & \\
\hline MS4 & & 0.868 & & & \\
\hline MS3 & & 0.819 & & & \\
\hline MS5 & & 0.806 & & & \\
\hline MS6 & & 0.699 & & & \\
\hline Infra7 & & & 0.860 & & \\
\hline Infra4 & & & 0.852 & & \\
\hline Infra6 & & & 0.802 & & \\
\hline Inter-Acc2 & & & & 0.774 & \\
\hline Inter-Acc1 & & & & 0.766 & \\
\hline Inter-Acc3 & & & & 0.742 & \\
\hline Univ-P2 & & & & & 0.915 \\
\hline Univ-P1 & & & & & 0.886 \\
\hline Eigenvalues & 3.226 & 2.961 & 2.384 & 2.109 & 1.861 \\
\hline$\%$ of Variance explained & 20.162 & 18.509 & 14.900 & 13.183 & 11.631 \\
\hline Cronbach's $\alpha$ & 0.894 & 0.882 & 0.846 & 0.790 & 0.860 \\
\hline
\end{tabular}

\subsection{Hypotheses testing}

After assuring basic parametric assumptions, simultaneous multiple regression was performed to ascertain a) what is the magnitude of the overall relationship among the determinants of organization's external factors (predictors) and commitment in the use of technology (outcome variable); b) and how much each of the predictor variables (i.e., Internet Accessibility, Management System, Infrastructure, and organization ICT policy) exclusively contributed to predicting commitment in the use of technology. 


\subsection{Simultaneous multiple regression}

Next, [Table 5] shows the results of hypotheses testing through simultaneous regression analysis for predicting 'commitment in the use of technology' (outcome variable). The grouping of variables significantly predicted over 39.5 percent of the total variance in predicting 'commitment in the use of technology'. The hypothesized regression model for this research study was significant $(\mathrm{F}(4,295=49.748, \mathrm{p}<0.001)$, with only three variables that significantly predicted 'commitment in the use of technology' except 'university ICT policy'. The value of $\beta$ depicts the relationship between the outcome variable and predictors. In Table $\mathrm{V}$, it is evident that the sign of the $\beta$ values of the three predictors are positive while one predictor is negative. This shows that 'Internet Accessibility', 'Management System', and 'Infrastructure' have a positive significant impact on 'commitment in the use of technology'. On the other hand, 'organization ICT policy' has a negative insignificant impact on 'commitment in the use of technology'. The issue of multicollinearity does not exist among the predictor variables since the Variance Inflation Factor (VIF) is less than 10. Multicollinearity existed if the VIF is greater than 10 .

Table 5. Hypotheses testing through simultaneous regression analysis

\begin{tabular}{|c|c|c|c|c|c|c|c|c|}
\hline Hypo. & Predictor & $\beta$ & SE & t -stat. & Sig. & VIF & Relationship & Remarks \\
\hline & Const. & 0.791 & 0.27 & 2.980 & 0.003 & & & \\
\hline H1 & IA & 0.371 & 0.07 & 5.068 & 0.000 & 1.530 & Positive & Supported \\
\hline H2 & MS & 0.352 & 0.05 & 6.621 & 0.000 & 1.365 & Positive & Supported \\
\hline H3 & Infra & 0.155 & 0.04 & 3.609 & 0.000 & 1.301 & Positive & Supported \\
\hline H4 & Univ-P & -0.036 & 0.04 & -0.811 & 0.418 & 1.175 & Negative & Not- Supported \\
\hline
\end{tabular}

The coefficients of parameter estimates suggest that 'Internet Accessibility' $(0.371 ; \mathrm{t}=$ $5.068, \mathrm{p}<0.05)$, 'Management System' $(0.352 ; \mathrm{t}=6.621, \mathrm{p}<0.05)$, and 'Infrastructure' $(0.155 ; \mathrm{t}=3.609, \mathrm{p}<0.05)$, reflect a statistically significant impact on 'commitment in use of technology'. Thus, three respective hypotheses (H1, H2, and $\mathrm{H} 3$ ) were supported respectively. On the other hand, 'organization ICT policy' $(-0.036 ; t=-0.811, p<0.05)$ has shown a statistically insignificant impact in predicting 'commitment in use of technology', thus (H4) was not supported. The following equation shows the regression equation to predict 'commitment in use of technology':

$$
\mathrm{CUT}=0.791+0.371(\mathrm{IA})+0.352(\mathrm{MS})+0.155(\text { INFRA })-0.036(\mathrm{UP})
$$

\section{Discussion}

Overall, the results provided evidence that internet accessibility, management system, and infrastructure have a significant positive impact on the commitment to the use of technology. However, ICT Policy has an insignificant negative impact on the commitment to the use of technology. The findings could be generalized to other public sector universities of the Republic of Yemen.

The current research makes important contributions to the theory of reasoned action, in addition to the aforementioned contributions to the technology acceptance model and theory of reasoned action. Furthermore, to the aforementioned contributions made to the Technology Acceptance Model (TAM) and Reasoned Action (TRA), the current study makes significant contributions to both theories. The study not only confirms the findings of the previous research but extends the literature in the area of the impact of internal and external factors on 
the use of technology in higher education. The study confirms that the influence of Internet Accessibility, Management System, and Infrastructure have a significant positive impact on the commitment in the use of technology. Thus, the current study provides both replication and generalization. Similarly, the same is confirmed by Al-Mulhem who reported that encouraging teachers to use and adopt e-learning programs, infrastructure, and technology resources are very important. Moreover, inadequate technical supports also create stress among teachers, which might affect teachers' readiness to integrate technology [21].

About the importance of the technical coordinator, Smerdon et al. stated that the absence of technical support hindered teachers to integrate technology in the classroom. It was also confirmed from their study that teachers who were provided technical support proven to be better than teachers who were not provided technical support. A similar result was found by Tar that those teachers who have the facility of computers and internet in their institute are still not using them in their lecture daily as they were not provided technical support to handle those hardware and software. The administration must provide training to the teachers so that they can use computers and plan their lessons accordingly. Leaders are responsible to motivate their staff towards integration technology in their teaching by providing them professional development workshops [14]. According to Munir and Khan, the non-supportive administrative staff is one of the main hindrances which prevent teachers to integrate ICT in their teaching. The active technology program needs help from the entire organization [30]. This was also discussed in the study conducted by Harasim that those institutes where administration includes technical support in their long-term plan, promote technology in their teaching, especially in online teaching in a better way as compared to those where administration support is absent.

However, the current study has challenged the findings of previous research that ICT policies have a significant negative impact on the commitment to the use of technology. Findings of the study suggest that management systems and availability of infrastructure play a more important role in the commitment of use of technology as compared to policy guidelines of organizations. Policy guidelines don't matter if infrastructure and support from management are not available. Regarding external factors, in 2015, Albugami and Ahmed found that Yemeni's educational policies are not clear, the contradiction was also found in between the instructions and the responsibilities. It was also found in the study that even though the Ministry of Education emphasizes the use of technology in education from beginning to school it is not providing sufficient support in terms of ICT resources, infrastructure, and ICT training to all staff. If the teachers and headmasters do not understand the policies, they will not apply them in their teaching, resulting in the absence of ICT integration in their teaching [6].

\section{Conclusion}

The current study examines the impact of external/environmental factors on the commitment to the use of technology. The objectives of the current study were to ascertain the association and current trends between research variables. A Quantitative approach by survey technique was preferred to answer the research question. The instrument was adopted and modified meticulously. A self-completion English and Arabic translated instrument was used to collect data. Initially, there was a total of 32 items in a questionnaire that fulfilled the minimum requirement in a research instrument. Moreover, the content and face validity of the research instrument was also determined with the assistance of field experts. The research instrument was translated and back-translated to ensure translation of scale's accuracy. Next, 
after conducting a pilot study and ensuring the initial reliability coefficient of the instrument, the main study was carried out. The instrument was disseminated using a Google form link to Thamar university's educators, staff, and students. A sample of 264 full-time employees having administrative and teaching responsibilities participated in our study in addition to students at different faculties.

After data collection, data screening, removal of outliers, multicollinearity was assessed. This statistical protocol was employed to check the correlation between independent variables. After satisfying this assumption, a total of 32 Likert-scale items related to external factors in our measurement model are categorized into five groups. Exploratory factor analysis was performed to ensure construct, convergent, and discriminant validity. In our study, all loaded items were greater than $|.50|$ which indicates a very robust convergent and construct validity. Furthermore, since there were no cross-loadings in our 'Component Transformation Matrix', therefore, the discriminant validity was also proven. Besides, all of the four organization's external factors demonstrated a significant correlation.

Cronbach coefficient Alpha of external factor one ('Internet Accessibility' $\alpha=0.894$ ) which has been found statistically significant to predict the "commitment in use of technology' $(0.371 ; \mathrm{t}=5.068, \mathrm{p}<0.05)$. Reliability of second external factor ('Management System' $\alpha=0.882$ ) has been found statistically significant to predict the 'commitment in the use of technology' $(0.352 ; \mathrm{t}=6.621, \mathrm{p}<0.05)$. The third external factor's reliability coefficient ('Infrastructure' $\alpha=0.846$ ) has also been found statistically significant to predict the 'commitment in the use of technology' $(0.155 ; \mathrm{t}=3.609, \mathrm{p}<0.05)$. The fourth external factor (organization ICT policy' $\alpha=0.860$ ) has shown a statistically insignificant impact ($0.036 ; \mathrm{t}=-0.811, \mathrm{p}<0.05)$ in predicting 'commitment in the use of technology'. In sum, the hypothesized model supports the theory which holds that the external factors of Thamar University: Internet accessibility, management system, and infrastructure except ICT policies have a significant positive impact on commitment in the use of technology.

\section{Recommendations}

The findings of the study suggest that infrastructure, technical support, and administrative support are significantly related to the teachers' commitment to the use of technology. Previous researches also support these external factors that need to be considered when investigating the teachers' commitment to the use of technology. The theoretical framework developed in this study can be adapted for other studies to implement ICT in education at a higher education level. Furthermore, in-service and trainee teachers should take advantage of using a learning management system. Faculty should create a positive learning environment in their online classes so the learners can take a benefit out of the immense investment in ICT by the ministry of higher education. Apart from giving training to teaching staff in the use of technology, learners should also be given a platform to increase and improve their digital literacy. Workshops can be conducted frequently for both teachers and learners. Faculty can offer additional and out of the class support to their reluctant and weak students to assist them in the use of technology.

\section{Limitations and future research}

The data were collected from one public sector university of Thamar province, Republic of Yemen. Only four external factors were taken into consideration in investigating its influence on the commitment to the use of technology. There could be other external/environmental factors that might be useful to underpin the theory and advance literature. Professional 
development and training are also considered as some of the external factors, which can also be studied to explore their effects on teachers' commitment to integrating ICT. A quantitative research design was implemented in this study, mixed-method research can be suggested for future research to get in-depth information about the external barriers. Moderating effects of demographic variables such as gender, age, years of teaching experiences, etc. can also be measured to find the effects on the commitment of teachers to use of technology with the external barrier. The present study may not reflect the commitment of private university teachers to implement ICT in teaching. So, in the future, it is also recommended to conduct the same study with the same external barriers in private universities. This study was limited to only external factors, for future in relation with external factors; internal factors such as user personal belief, attitude, and behavior can also be studied which hindered or supports teachers to integrate ICT in their teaching.

\section{Disclosure statement}

No potential conflict of interest was reported by the authors.

\section{References}

[1] A. K. Arora and R. Srinivasan, "Impact of pandemic COVID-19 on the teaching-learning process: A study of higher education teachers," Indian Journal of Management, vol.13 no.4, pp.43-56, (2020), 10.17010/pijom/2020/v13i4/151825

[2] A. M. Al Ansi and A. Al-Ansi, "Future of education post-covid-19 pandemic: Reviewing changes in learning environments and latest trends," Solid State Technology, vol.63. no.6, pp.201584-201600, (2020)

[3] A. M. Al-Ansi and A. M. Suprayogo, "Impact of information and communication technology (ICT) on different settings of the learning process in developing countries," Science and Technology, vol.9, no.2, pp.19-28, (2019)

[4] L. E. Japhet and T. A. Usman, "Factors that influence teachers' adoption and integration of ICT in teaching/learning process,” Educational Media International, vol.55, no.1, pp.79-105, DOI:10.1080/09523987.2018.1439712, (2018)

[5] .A. Garad and A. M., and Q. I. N. Al-Ansi, "The role of e-learning infrastructure and cognitive competence in distance learning effectiveness during the covid-19 pandemic," Jurnal Cakrawala Pendidikan, vol.40, no.1, (2021)

[6] T. B. T. Ahmed, "Between school factors and teacher factors: What inhibits Malaysian science teachers from using ICT?” Malaysian Online Journal of Educational Technology, vol. 2, no.1, pp.1-10, (2014)

[7] J. W. Hur and D. A. W. S. Shannon, "An investigation of relationships between internal and external factors affecting technology integration in classrooms," Journal of Digital Learning in Teacher Education, vol.32, no.3, pp.105-114, 2016, (2020)

[8] W. Veen, "The role of beliefs in the use of information technology: implications for teacher education, or teaching the right thing at the right time" Journal of Information Technology for Teacher Education, vol.2, no.2, pp.139-153

[9] A. M. Al-Ansi, "Student's anxiety and recruitment during COVID-19 pandemic: Role of university, specialization and employment expectation," Perspektivy nauki i obrazovania-Perspectives of Science and Education, vol.49, no.1, pp.404-413, (2021)

[10] A. M. Al-Ansi, "Reforming education system in developing countries," International Journal of Education and Research, vol.5, no.7, July, (2017)

[11] S. Alshmrany and B. Wilkinson, "Factors influencing the adoption of ICT by teachers in primary schools in Saudi Arabia” International Journal of Advanced Computer Science and Applications, vol.8, no.12, pp.143156, (2017) 
[12] M. A. Barri, "What makes web-enhanced learning successful: Four key elements" International Journal of Technology Enhanced Learning, vol.12, no.4, pp.426-446, DOI:10.1504/IJTEL.2020.110051, (2020)

[13] A. G. Almekhlafi and F. A. Almeqdadi, "Teachers' perceptions of technology integration in the United Arab Emirates school classrooms" Journal of Educational Technology and Society, vol.13, no.1, pp.165-175, (2010)

[14] S. Muzafar and N. Z. Jhanjhi, "Success stories of ICT implementation in Saudi Arabia in employing recent technologies for improved digital governance," pp.151-163, Hershey, PA: IGI Global. DOI:10.4018/978-17998-1851-9.ch008, (2020)

[15] N. Atman-Uslu and Y. K. Usluel, "Predicting technology integration based on a conceptual framework for ICT use in education" Technology, Pedagogy and Education, vol.28, no.5, pp.517-531, (2019)

[16] C. Bulut and O. Culha, "The effects of organizational training on organizational commitment" International Journal of Training and Development, vol.14, no.4, pp.309-322, DOI:10.1111/j.1468-2419.2010.00360.x, (2010)

[17] M. Fishbein and I. Ajzen, "Belief, attitude, intention, and behavior: An introduction to theory and research," Reading, MA: Addison-Wesley

[18] F. D. Davis and R. P. a. W. P. R. Bagozzi, "User acceptance of computer technology," Journal of Management Science, vol.35, no.8, pp.982-1003, https://www.jstor.org/stable/2632151

[19] T. Ramayah, K. Rouibah, and M. a. R. G. J. Gopi, “A decomposed theory of reasoned action to explain intention to use internet stock trading among Malaysian investors," Computers in Human Behavior, vol.25 no.6, pp.1222-1230, (2009)

[20] E. Toprakci, "Obstacles at the integration of schools into information and communication technologies by taking into consideration the opinions of the teachers and principals of primary and secondary schools in Turkey," Journal of Instructional Science and Technology, vol.9, no.1, pp.1-16, (2006)

[21] B. Smerdon, S. Cronen, and L. A. J. I. N. a. A. J. Lanahan, "Teachers' tools for the 21 st century: A report on teachers' use of technology," Statistical Analysis Report, (2000)

[22] M. Spiteri and S. C. Rundgren, "Literature review on the factors affecting primary teachers' use of digital technology," Technology Knowledge and Learning, vol.25, no.1, pp.115-128, DOI:10.1007/s10758-0189376-x, (2020)

[23] D. M. Herold, D. B. Fedor, and S. a. L. Y. Caldwell, "The effects of transformational and change leadership on employees' commitment to a change: A multilevel study," Journal of Applied Psychology, vol.93, no.2, pp.346-357, (2008)

[24] S. K. Piderit, "Rethinking resistance and recognizing ambivalence: A multidimensional view of attitudes toward an organizational change" Academy of Management Review, vol.25, no.4, pp.783-794, (2000)

[25] L. a. M. J. P. Herscovitch, "Commitment to organizational change: Extension of a three-component model," Journal of Applied Psychology, vol.87, no.3, pp.474-487, DOI:10.1037/0021-9010.87.3.474, (2002)

[26] K. Amoako-Gyampah and J. a. L. K. W. Meredith, "Using a social capital lens to identify the mechanisms of top management commitment: A case study of a technology project," Project Management Journal, vol.49, no.1, pp.79-95, (2018)

[27] Y. Akubulut and M. a. O. F. Kesim, "Construct validation of ICT indicators measurement scale (ICTIMS)," vol.3, no.3, pp.60-77, (2007)

[28] S. S. a. K. I. Munir, "Practices and integration of ICT at private higher secondary level in Pakistan," International Journal on New Trends in Education and their Implications, vol.6, no.2, pp.93-104, (2015)

[29] E. Osika and R. a. B. R. Johnson, "Factors influencing faculty use of technology in online instruction: A case study," Online Journal of Distance Learning Administration, vol.12, no.1, (2009)

[30] L. Harasim, "Learning theory and online technologies," New York, Taylor and Francis, DOI:10.4324/9781315716831, (2017)

[31] U. Sekaran and R. Bougie, "Research methods for business for a skill-building approach," John Willey and Sons, Inc. New York, (2003) 
[32] M. Saunders and P. a. T. A. Lewis, "Research methods for business students, (7th ed.)," Pearson Education Limited, (2016)

[33] E. R. Babbie, “The basics of social research,” Belmont, CA: Wadsworth Thomson Learning, (2008)

[34] C. R. Kothari, "Research methodology: Methods and techniques," New Age International (pvt) Ltd., (2004)

[35] A. Bryman, "Social research methods," Oxford University Press, (2012)

[36] J. F. Hair, W. C. Black, and B. J. A. R. E. a. T. R. L. Babin, "Multivariate data analysis, (6th ed.)," Englewood Cliffs, NJ: Prentice-Hall, (2006)

[37] N. a. H. O. Dalkey, "An experimental application of the Delphi method to the use of experts," Management Science, vol.9, no.3, pp.458-467, DOI:10.1287/mnsc.9.3.458. HDL:2027/inu.30000029301680

[38] H. Sackman, "Delphi assessment: Expert opinion," Forecasting and group process, R-1283-PR, April, Brown, Thomas, An Experiment in Probabilistic Forecasting, R- 944-ARPA, 1972, 1974

[39] A. L. T. a. M. Harold, “The Delphi method: Techniques and applications, reading," mass, Addison-Wesley

[40] W. L. Neuman, "Basics of social research: Qualitative and quantitative approaches," Pearson Education, Inc., (2007)

[41] T. R. Black, "Doing quantitative research in the social sciences: An integrated approach to research design," Measurement and Statistics, London, Sage Publication

[42] D. a. M. P. George, "SPSS for windows step by step: A simple guide and reference," Boston: Allyn and Bacon, (2003)

[43] J. Nunnaly, "Psychometric theory," New York: McGraw-Hill

[44] J. F. Hair, W. C. Black, and B. J. a. A. R. E. Babin, "Multivariate data analysis," New York: The Prentice Hall, (2010)

[45] M. J. a. W. D. S. Polonsky, "Designing and managing a research project: A business student's guide," Thousand Oaks, CA: Sage Publications Inc., (2010)

[46] I. A. R. a. A. S. Etikan, "Comparison of snowball sampling and sequential sampling technique," Biometrics and Biostatistics International Journal, vol.3, no.1, pp.1-2, DOI:10.15406/bbij.2015.03.00055, (2015)

[47] K. Seifu, "Determinants of information and communication technology integration in teaching-learning process at Aksum University," Cogent Education, vol.7, no.1, pp.1-23, DOI:10.1080/2331186X.2020.1824577, (2020)

[48] B. G. a. F. L. S. Tabachnick, "Using multivariate statistics," Boston: Pearson Education, (2007)

[49] J. Pallant, "SPSS survival manual," (4th ed) Maidenhead, PA: Open University Press, (2011)

[50] P. M. M. S. B. L. J.-Y. a. P. N. P. Podsakoff, "Common method biases in behavioral research: A critical review of the literature and recommended remedies," Journal of Applied Psychology, vol.88, no.5, pp.879903, (2003)

[51] P. Tharenou and R. a. C. B. Donohue, "Management research methods," Cambridge, MA: Cambridge University Press, (2007)

[52] J. P. Stevens, “Applied multivariate statistics for the social sciences,” New York: Routledge, (2012) 
Implementation of ICT at University Level During Covid-19 Pandemic: An Evidence from Yemen

This page is empty by intention. 